\title{
Chemical reactions at surfaces and interfaces from first principles: Theory and application*
}

\author{
Zhi-Pan Liu \\ Department of Chemistry, University of Cambridge, Cambridge, CB1 2EW, UK
}

\begin{abstract}
The last decade has seen rapid expansion and development in the field of density functional theory (DFT) simulation on the complex chemical processes that occur at surfaces and interfaces. The understanding of the phenomena in surface science and heterogeneous catalysis has benefited tremendously from these quantum mechanic calculations. This article reviews current progress in the theory of reactions on surfaces, in particular, those relevant to the barrier and the active site of surface reactions. Two representative reactions, namely, NO dissociation and $\mathrm{CO}$ oxidation, are selected to illustrate how these theoretical concepts are applied to understand catalytic reactions. Here, the pathways and energetics of these reactions under various catalytic conditions are described in detail, and the understanding of the reactions is generalized. It is concluded that DFT-based methods can be well applied to catalysis to understand the electronic structure of chemical processes and to elucidate mechanisms of complex surface reactions.
\end{abstract}

\section{INTRODUCTION}

There is little doubt that most of low-energy physics, chemistry, and biology can be explained by modern quantum theory. It has been demonstrated that the ability of quantum mechanics to predict the total energy of a system of electrons and nuclei enable one to reap a tremendous benefit. The first-principles, total-energy calculation can predict the important quantities such as atomic structures and bonding energies, and may further provide key information on chemical reactions. Indeed, amongst the most challenging and exciting of fields into which the first-principles theory is currently expanding must rank the study of chemical reactions on surfaces, the central issue in heterogeneous catalysis [1-4]. Here, the quantum theory describing the molecule-surface interaction and the classical dynamics of molecular movement come into play to determine the mechanism of catalytic processes.

A long-standing goal of researchers in the field of catalysis is to develop a general theoretical framework to understand and predict the phenomena in catalysis. It is believed that the design of new catalysts can be largely facilitated if the activity and selectivity of catalysts can be predicted given knowledge only of catalyst composition, structure, and reaction conditions. Traditional tools in chemistry, such as frontier orbital theory, Marcus theory, and Brønsted-Evans-Polanyi (BEP) principle [5-6], often do not work well in explaining the reactivity in heterogeneous catalysis, not least because of the complex nature of the interaction between molecules and surfaces. On the other hand, the application of the first-principles theory in catalysis has been hindered for years because of the lack of both hardware (i.e., powerful computers) and software (e.g., efficient theoretical methods/algorithms to solve quantum equations). It was not until the early 1990s that the first-principles calculation within the den-

*Pure Appl. Chem. 76, 2051-2099 (2004). A collection of invited, peer-reviewed articles by the winners of the 2004 IUPAC Prize for Young Chemists. 
sity functional theory (DFT) framework became affordable on workstations for studying the simplest surface reaction, i.e., $\mathrm{H}_{2}$ dissociation on surfaces [7-8].

Since then, both the size and the complexity of the system studied using DFT have increased dramatically, from small clusters of several atoms, to flat single-crystal surfaces, and to multicomponent, defected systems of hundreds of atoms. To date, many elementary surface reactions have been studied in detail by DFT, and significant advances in the field have been achieved. This article is intended to review current progress in the theory of surface reactions and its application in understanding catalytic processes. For this purpose, DFT calculation results on two catalytic reactions, NO dissociation $\left(\mathrm{NO} \rightarrow \mathrm{N}+\mathrm{O}\right.$ ) and $\mathrm{CO}$ oxidation $\left(2 \mathrm{CO}+\mathrm{O}_{2} \rightarrow 2 \mathrm{CO}_{2}\right)$ on metal catalysts are collected and elaborated. The former reaction belongs to dissociation reactions, and the latter one is an association reaction. The achieved understanding on the two distinct types of reactions illustrates well how the current theoretical framework can be applied to catalysis in general. The paper is organized as follows: DFT methods used to study surface reactions are sketched in the second section. The third section reviews some of the recent progress in the theory of surface reactions. In the fourth section, accumulated DFT results in NO dissociation and CO oxidation will be presented. Concluding remarks are outlined in the fifth section.

\section{DENSITY FUNCTIONAL THEORY APPROACH TO REACTIONS ON SURFACES}

An accurate description of molecule-surface interactions is the first step toward a fundamental understanding of reactions on surfaces. The modeling of surfaces using the first-principles methods was, however, a formidable task for many years [9], and a breakthrough in the field was only made with the advent of DFT and powerful computers in the late 1980s. For the detailed formulisms of DFT, interested readers may refer to the monograph of Parr and Yang [10]. In general, DFT starts with a consideration of the entire electron density of the system based on the foundation work of Hohenberg and Kohn [11-12], in which ground-state total electronic energy is proved to be a function of the electron density. In the framework of DFT, the nonclassical part of electron-electron interaction energy, namely electron-electron exchange and correlation, can be expressed as a unified function of a single variable, i.e., the total electron density, which is much simpler compared to the traditional Hartree-Fock approach. Although the exact form of the exchange-correlation functional is yet unknown, many approximate functionals have been proposed in practice, such as local density approximation (LDA) and its derived versions of generalized gradient approximation (GGA) [13-14]. It has been demonstrated that, in general, GGA results can reproduce good structures up to the experimental accuracy and fairly well bond energies within error of a few percents compared to experimental results. Current GGA calculations provide a rather robust basis for a systematic comparison with experiment results (see, e.g., [3]).

To model extended surface systems, a so-called supercell approach is currently used, in which the structure of the surface is repeated both vertically and laterally [15]. The theory underlined the supercell approach is Bloch's theorem [16a], in which a wavefunction is split into two relatively simple parts owing to the periodicity of the system. By integrating DFT, Bloch's theorem, and many other elegant methods/algorithms [16], such as ultrasoft pseudopotential method [16b], iterative minimization scheme [15,16c], Broyden's method for density mixing [16d], fast Fourier transform method, and so on, the state-of-the-art computational package is able to solve the electronic structure of systems up to hundreds of atoms with great efficiency.

It should be emphasized that the three-dimensional periodicity imposed by the supercell approach implies that the surface is modeled as an infinite $s l a b$ of finite thickness. As a result, a sufficient number of surface layers and a sufficiently large vacuum region between slabs are essential to produce acceptable results. Although being a method designed for calculating periodical systems, the supercell approach can also be applied to aperiodical systems [15] as long as the modeled supercell is large enough so that the lateral interaction between the aperiodical elements is negligible. This feature is vital to the study of surface reactions. First, the periodicity often exists for a clean or adsorbate-covered surface, 
but is always not present for a reaction on the surface. Second, the systematic errors can be largely cancelled if all the calculations are treated in the same theoretical framework. In such a way, the calculation can converge much faster with respect to calculation setups.

Using DFT, the forces on atoms can be calculated based on Hellmann-Feynman theorem. With the forces acting on atoms being computed, the structure-optimization techniques, such as BFGS method [16e], molecular dynamics [15,16c], and transition state (TS) search techniques can then be used to determine the various states along a reaction pathway, e.g., the initial state (IS), the TS, and the final state (FS). The calculated pathways and energetics provide important information on the reaction mechanism. Among the techniques, the TS search technique is perhaps the most sophisticated because a TS is not a stable point, but a saddle point along a reaction pathway. In recent years, two different approaches to locate TS have been successfully used for studying surface reactions: (i) constrained minimization method [17] and (ii) nudged elastic band method [18].

Finally, it is worth mentioning that the current first-principles total energy methods compute only the electronic energy of a system and the effects of the environment, such as the temperature and the pressure, are not taken into account explicitly. Although the calculated results may compare comfortably with those from the experiment under the ultra-high vacuum and low-temperature conditions, care should be taken if one would extrapolate directly these results to the situations where the environmental conditions play crucial roles. In order to produce more accurate descriptions for real systems, some DFT-based hybrid methods have been developed in recent years, for example, molecular dynamics at constant temperatures [19], ab initio thermodynamics [20], and kinetic Monte Carlo [21].

\section{RECENT PROGRESS IN THE THEORY OF SURFACE REACTIONS}

\section{Barrier $\left(E_{\mathrm{a}}\right)$ of surface reactions}

The dissociation of molecules is one of the most important reactions in catalysis. It is the first step and often the rate-determining step in many catalytic processes. Therefore, dissociation reactions have been extensively studied both experimentally and theoretically in the last 50 years. One of the important findings in recent years is that for dissociation reaction on surfaces the barrier depends linearly on the reaction energy, $\Delta H$, that is the enthalpy change from the gas-phase molecule to the dissociated products on the surface. This relation was first established for hydrocarbon, $\mathrm{CO}, \mathrm{NO}$, and $\mathrm{N}_{2}$ dissociation reactions based on DFT calculations by several groups, and was then shown to be valid for many other dissociation reactions [22-25]. By linking the barrier with the exothermicity of the reaction, such relation is best known as the BEP relation in chemistry [5], which has often been assumed implicitly to hold for surface reactions. It is only recently with the extensive use of DFT calculations that the relation for surface reactions can be verified and established on the basis of quantum mechanics.

DFT calculations showed that the slope of the linear relation between the dissociation barrier and the reaction energy is, however, far larger than the value 0.5 suggested by the traditionally regarded BEP relation and derived from Marcus equation mathematically [5-6]. By studying $\mathrm{CO}$ dissociation on a group of $4 \mathrm{~d}$ and $5 \mathrm{~d}$ late transition-metal surfaces, Liu and $\mathrm{Hu}$ [25a] found that the linear relationship between the barrier and the reaction energy has a slope being close to 1. It points out that the FS stability can affect the barrier of dissociation reactions dramatically. In order to explain this, they decomposed the dissociation barrier, $E_{\mathrm{a}}^{\text {dis }}$, as:

$$
E_{\mathrm{a}}^{\mathrm{dis}}=E_{\mathrm{a}}^{\mathrm{ass}}+E_{\mathrm{bond}}-E_{\mathrm{FS}}
$$

where $E_{\mathrm{a}}^{\text {ass }}$ is the barrier of the reverse reaction (association), $E_{\mathrm{bond}}$ is the bond strength of the breaking bond, which is constant for a reaction, and $E_{\mathrm{FS}}$ is the total chemisorption energy of dissociation products. Hence, $E_{\mathrm{bond}}-E_{\mathrm{FS}}$ is the reaction energy, $\Delta H$. Shown in Fig. 1 is the plot $E_{\mathrm{a}}^{\text {dis }}$ vs. $E_{\mathrm{FS}}$. The origin of the linear relation in Fig. 1 is that the change of $E_{\mathrm{a}}^{\text {ass }}$ is much smaller (one order of magnitude) 


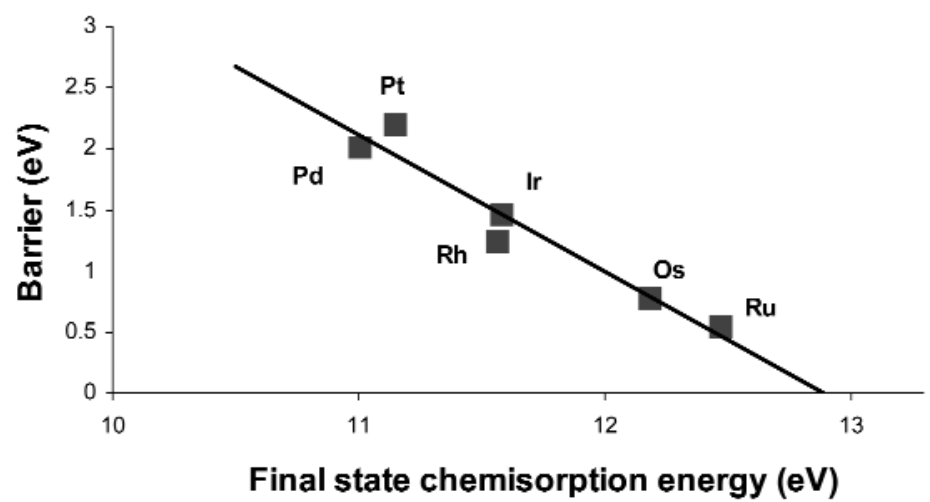

Fig. 1 Linear dependency of dissociation barrier on FS stability. Data taken from [25a].

than that of $E_{\mathrm{FS}}$ with the variation of the metal substrate. Therefore, $E_{\mathrm{a}}^{\mathrm{dis}}$ is determined by $E_{\mathrm{FS}}$. This explanation is also valid for other dissociation reactions [25b].

Compared to dissociation reactions, the barrier of association reactions is more complex. It was realized that a BEP-like relation does not stand for association reactions since the exothermicity $(\Delta H)$ alone often cannot determine the barrier. Using a barrier decomposition method, Liu et al. [26,27] suggested that there are three main contributions to an association barrier: (i) the direct Pauli repulsion between the reactants, (ii) the so-called bonding competition energy, and (iii) the energy contribution from the potential energy surface (PES) of the reactants. They are elaborated in the following.

The Pauli repulsion was long realized to be a fundamental reason for the existence of the barrier to a reaction. Based on the perturbation theory, the Pauli repulsion energy cost can be considered as an energy term due to the overlap of occupied molecular orbitals [6]. On surfaces, the energy cost due to the direct Pauli repulsion between the reactants is dictated by the saturation of the reactants, which is presumably related to their gas-phase valency. DFT calculations showed that the adsorbate with a higher valency (thus, less saturated) is often more reactive. It was found that in the hydrogenation reactions $(\mathrm{X}+\mathrm{H} \rightarrow \mathrm{XH}, \mathrm{X}=\mathrm{C}, \mathrm{N}$, and $\mathrm{O})$ and the oxidation reactions $(\mathrm{X}+\mathrm{O} \rightarrow \mathrm{XO}$ reaction) on metal surfaces [26,27], the adsorbed $\mathrm{C}$ atom is the most active, whereas the adsorbed $\mathrm{O}$ atom is the most inert among the $\mathrm{C}, \mathrm{N}$, and $\mathrm{O}$ atoms. On $\mathrm{Rh}\{111\}$, for instance, the barrier of $\mathrm{C}+\mathrm{H} \rightarrow \mathrm{CH}, \mathrm{N}+\mathrm{H} \rightarrow \mathrm{NH}$, and $\mathrm{O}+\mathrm{H} \rightarrow \mathrm{OH}$ is calculated to be $0.72,0.99$, and $1.32 \mathrm{eV}$, respectively [26]. Fischer-Tropsch reaction $\left(\mathrm{CO}+\mathrm{H}_{2} \rightarrow\right.$ long-chain hydrocarbon) may be another good example. Liu and Hu found that on Ru surfaces the reactions involving $\mathrm{C}, \mathrm{CR}$ species $(\mathrm{R}=$ alkyl) have lower barriers compared to those involving $\mathrm{CH}_{2}, \mathrm{CH}_{3}$ species generally. Based on that, they suggested that the atomic $\mathrm{C}$ and $\mathrm{CR}(\mathrm{R}=$ alkyl) species be the active species in the chain-growth process [28].

The bonding competition effect is a rather unique feature of surface reactions. It is caused by the simultaneous bonding of reactants with the same substrate metal atom. Since most adsorbates, including molecules and atoms, tend to bond similarly with the metal valence states, a surface-mediated repulsion will be induced as two adsorbates come close to bond with the same metal atom [27,29-31]. Figure 2 explains this well, which plots the variation of the projected $d$ density of states (DOS) of a Ir atom before and after the adsorption of a $\mathrm{NO}, \mathrm{N}$ atom, and $\mathrm{O}$ atom, respectively. It shows clearly that the metal $d$ states near the Fermi level are most responsible for the bonding with the valence states of the $\mathrm{NO}, \mathrm{N}$ atom, $\mathrm{O}$ atom. Upon the adsorption of one adsorbate, the metal $d$ states are largely stabilized, which is reflected by the increase of DOS at the low-energy region, and thus become inert to bond with the second adsorbate [31]. It was further found that the bonding competition energy cost is related to the saturation of metal valence states as well as the reactants' bonding ability [32]. For example, DFT calculations showed that at late transition-metal surfaces, e.g., Pt and Pd, where the metal $d$-states are 


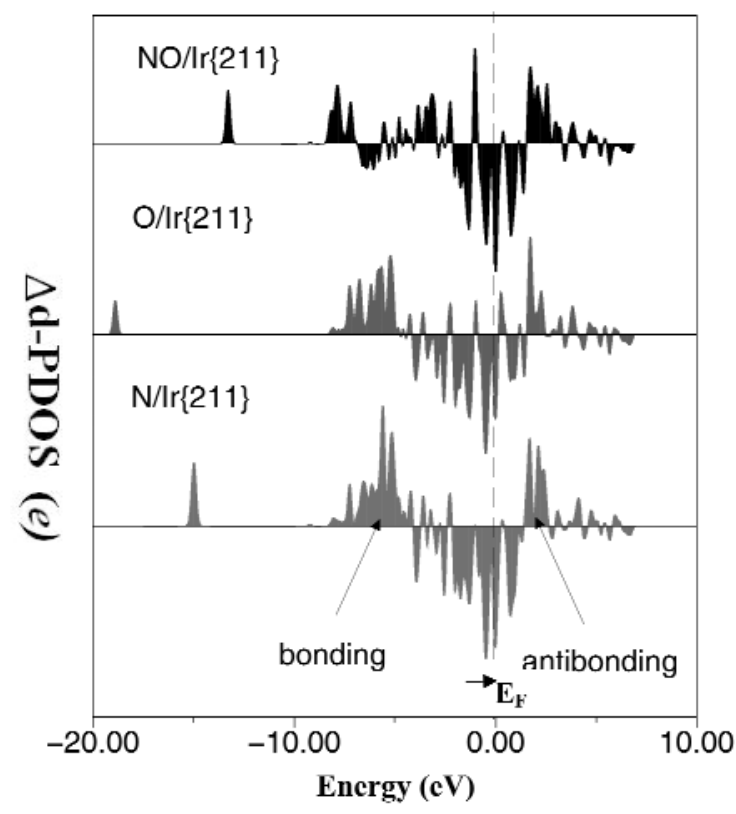

Fig. 2 Plots showing the physical origin of the bonding competition effect and its relation to the adsorbate valency. The plots are the difference of the $d$-states projected density of states ( $\Delta$ d-PDOS) of a step-edge Ir metal (on $\operatorname{Ir}\{211\}$ ) before and after the adsorption of $\mathrm{NO}, \mathrm{O}$, and $\mathrm{N}$, respectively. The adsorption site of $\mathrm{NO}, \mathrm{O}$, and $\mathrm{N}$ is at the step-bridge site on $\operatorname{Ir}\{211\}$. All the $\Delta$ d-PDOSs are lined up with the Fermi level $\left(E_{\mathrm{F}}\right)$, which is set to be energy zero. From [31].

close to be full, the bonding competition energy is higher than that at the early metals such as $\mathrm{Ru}, \mathrm{Rh}$ [32].

It should be emphasized that the bonding competition effect can often be avoided in surface reactions because of the activation of reactants to other sites to react, such as the less-coordinated atop sites and the sites at the more open surfaces, stepped and kinked surfaces [26,27,31]. Such site-changing during a reaction is always at the expense of energy due to the PES corrugation of the reactant. Nevertheless, it may reduce the barrier because the bonding competition effect is quenched (the direct Pauli repulsion may be reduced as well) [26]. This is the reason why surface reactions usually have multiple pathways (TSs). CO oxidation is one such example, where the bonding competition is maximally avoided in the reaction, as will be discussed in the subsection " $\mathrm{CO}+\mathrm{O} \rightarrow \mathrm{CO}_{2}$ in $\mathrm{CO}$ oxidation". In this particular case, a BEP-like relation can be established to predict the barrier: the stronger the reactants, i.e., $\mathrm{CO}$ and $\mathrm{O}$, adsorb on the surface, the more difficult they can react [27].

\section{Active site for surface reactions}

To predict where a catalytic reaction should occur is another fundamental issue in catalysis [33]. It is known that some catalytic reactions such as ammonia synthesis are very sensitive to the change of catalyst structure, whereas some are quite insensitive, for example, methanation reaction and CO oxidation $[32,33]$. As the reaction rate depends exponentially on the reaction barrier according to Arrhenius law, the question of where a catalytic reaction should occur is, in fact, the one of where the reaction can occur with the lowest barrier [32].

Combining DFT and experimental techniques, the structure-sensitivity of the dissociation of diatomic molecules (e.g. $\mathrm{N}_{2}$, NO, $\mathrm{CO}$ ) has been investigated thoroughly in recent years, see for example, [32,34-36]. Using STM and DFT calculations, Dahl et al. found that the structure-sensitivity of am- 
monia synthesis on $\mathrm{Ru}$ is due to its rate-determining step, $\mathrm{N}_{2}$ dissociation, occurring dominantly at stepped surfaces [34]. They observed that the $\mathrm{N}-\mathrm{N}$ bond breaking on $\mathrm{Ru}\{0001\}$ is much slower than that on steps, and the reaction barrier on steps was calculated to be $\sim 1.5 \mathrm{eV}$ lower than that on flat surfaces. The same picture has been found earlier for NO dissociation on $\mathrm{Ru}\{0001\}$ [35-36]. Hammer suggested that the uplift of the $d$ band on steps, that is an electronic effect which stabilize adsorbates, is the main reason for the barrier reduction in NO dissociation [35]. However, Dahl et al. interpreted the large barrier reduction of $\mathrm{N}_{2}$ dissociation being mainly due to a beneficial geometrical effect at stepped sites [34].

To rationalize the structure-sensitivity phenomena in general, Liu and $\mathrm{Hu}$ studied $\mathrm{CH}_{4} \leftrightarrow \mathrm{CH}_{3}+\mathrm{H}$ and $\mathrm{CO} \leftrightarrow \mathrm{C}+\mathrm{O}$ reactions on flat, stepped, kinked $\mathrm{Rh}$, Pd surfaces using DFT [32]. They showed that surface defects, especially the steps, are generally favored for dissociation reactions owing to both the electronic and the geometrical effect at defects. On the other hand, association reactions can be either structure-sensitive or -insensitive. The reaction site of an association reaction is related to the bonding competition effect, which is determined by the reactant valency and the metal $d$ occupancy. It was revealed that reactions with high valency reactants are more likely to occur at defects (more structure-sensitive), as compared to reactions with low valency reactants. Similarly, the reactions on late transition metals (high $d$ occupancy) are more likely to proceed at defects than those on the early transition metals (low $d$ occupancy).

\section{APPLICATION OF THE THEORY TO UNDERSTAND CATALYTIC REACTIONS}

\section{$\mathrm{NO} \rightarrow \mathrm{N}+\mathrm{O}$ dissociation in the context of $\mathrm{NO}$ reduction}

NO reduction on transition metals is of great industrial importance, in particular for the after-treatment of vehicles [37-39]. NO dissociation is the key step in the process. The mechanism of NO reduction on transition metals is expected to follow the scheme shown in Fig. 3. The efficiency of NO dissociation is very much dependent on the environment under which NO reduction is operated. It can be either a reductive or an oxidative environment. In the reductive conditions, NO reduction is conducted in the presence of reductants, such as $\mathrm{CO}, \mathrm{H}_{2}$, or $\mathrm{NH}_{3}$, and $\mathrm{NO}$ dissociation is facilitated as the dissociated $\mathrm{O}$ atoms can be removed by reductants. This type of NO reduction can be catalyzed by a so-called threeway catalyst, which employs various combinations of $\mathrm{Pt}, \mathrm{Pd}$, and $\mathrm{Rh}$ for the simultaneous removal of $\mathrm{NO}, \mathrm{CO}$ and unburned hydrocarbons. In contrast, in the presence of excess $\mathrm{O}_{2}$ (the lean-burn condition) NO dissociation is hindered on the three-way catalysts. Platinum-group metal, in particular Pt, Ir-based catalysts are currently being intensively investigated in experiment for the lean-burn NO reduction [38-39]. Systematic DFT studies on NO reduction have been reported on several surfaces: NO reduction by $\mathrm{CO}$ on $\mathrm{Pt}\{100\}$ surface by Eichler and Hafner [40-41] and on Pd surfaces by Hammer [42]; NO reduction in the oxidative conditions on Ir surfaces by Liu et al. [31,43].

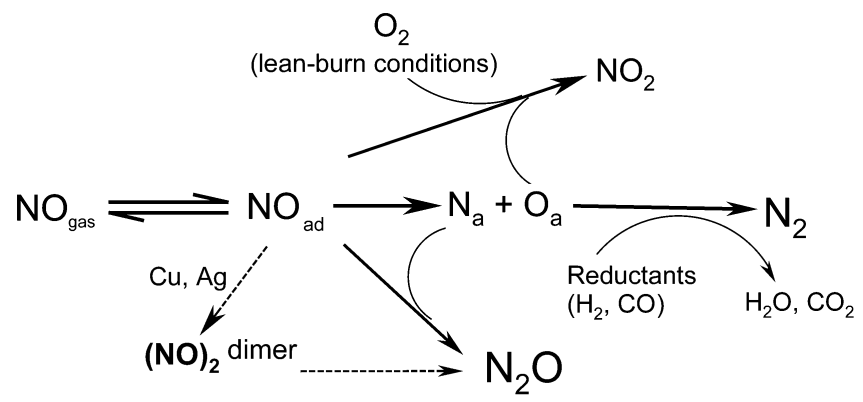

Fig. 3 Mechanism of NO reduction on metal surfaces. 
To date, NO dissociation has been investigated on a group of clean metal surfaces: Pd and Rh surfaces by Loffreda et al. [44,45]; Rh, Pd, Ru surfaces by Hammer [35,42]; Pt $\{100\}$ by Eichler [40,41]; Ir and Pt surfaces by Liu et al. [31,43]. By comparing $\mathrm{NO}$ dissociation with $\mathrm{N}_{2}, \mathrm{CO}$, and $\mathrm{O}_{2}$ dissociation reactions on metal surfaces, DFT studies showed that the dissociation of these diatomic molecules possess common features, which can be generalized as follows.

First, the TS of the dissociation reactions belongs to late TS (FS-like). As a result, the reaction barrier is to a large extent determined by the stability of the FS (as discussed in the subsection "Barrier $\left(E_{\mathrm{a}}\right)$ of surface reactions"). This feature has been observed by Hammer [42] for NO dissociation on Ru, $\mathrm{Rh}$, and Pd flat surfaces, by Liu and $\mathrm{Hu}[25 \mathrm{a}]$ for $\mathrm{CO}$ dissociation on $\mathrm{Ru}\{0001\}, \operatorname{Rh}\{111\}, \operatorname{Pd}\{111\}$, Os $\{0001\}$, $\operatorname{Ir}\{111\}$, and $\operatorname{Pt}\{111\}$, and also by Logadottir et al. [46] for $\mathrm{N}_{2}$ dissociation. The relation explains well the general consensus in experiment [37]: from left to right across the periodical table, NO dissociation became more and more difficult because the $\mathrm{N}$ and $\mathrm{O}$ bonding on the metals become weaker.

Second, the dissociation reactions are highly structure-sensitive. The stepped, edged, or open surfaces are generally much more active than the close-packed flat surface. For example, for NO dissociation on Ru, Hammer [35] showed that dissociation barrier at the Ru monatomic step is more than $1 \mathrm{eV}$ lower than that at the flat $\mathrm{Ru}\{0001\}$. The structure-sensitivity of NO dissociation can be understood by comparing the TS of NO dissociation on the close-packed flat surfaces and stepped surfaces, as illustrated in Fig. 4. At the TS on the flat surface, three (or four) metal atoms are involved in bonding with the $\mathrm{N}-\mathrm{O}$ TS complex and the $\mathrm{N}$ and $\mathrm{O}$ share bonding with one metal atom. In contrast, at the TS on the stepped surface, totally five atoms are involved in bonding with TS complex and no surface atom bonds simultaneously with the dissociating $\mathrm{N}$ and $\mathrm{O}[31,35,42-43]$. This indicates that on going from the flat surface to the stepped surface, the TS becomes more stable because of the enhanced coordination and the nonbonding competition geometry at steps.

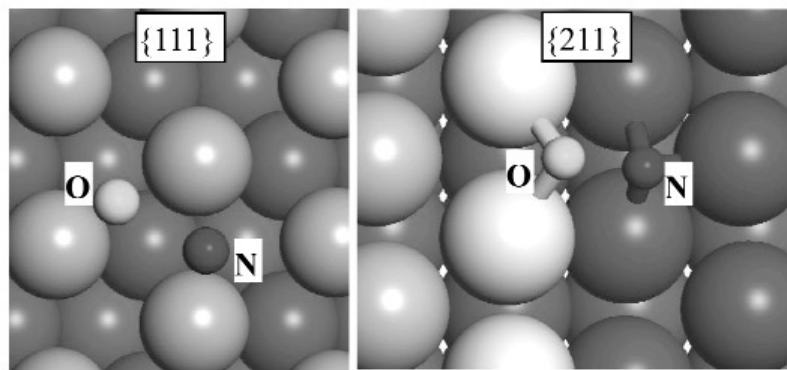

Fig. 4 Typical transition-state structures of NO dissociation on the close-packed $\{111\}$ surface and the stepped $\{211\}$ surface.

The effect of excess $\mathrm{O}_{2}$ on NO dissociation has been studied by Liu, Jenkins, and King [31,43] recently. It was shown that on the clean Ir steps, the $\mathrm{NO} \rightarrow \mathrm{N}+\mathrm{O}$ reaction $\left(E_{\mathrm{a}}=1.19 \mathrm{eV}\right)$ is much faster than its reverse reaction, i.e., $\mathrm{N}+\mathrm{O} \rightarrow \mathrm{NO}\left(E_{\mathrm{a}}=2.31 \mathrm{eV}\right)$. After half of the stepped sites are decorated with $\mathrm{O}$ atoms, the equilibrium of $\mathrm{NO} \leftrightarrow \mathrm{N}+\mathrm{O}$ reaction shifts toward the left-hand side: the $\mathrm{N}+\mathrm{O} \rightarrow \mathrm{NO}$ reaction becomes much easier and its barrier $(1.13 \mathrm{eV})$ is similar to the barrier of the $\mathrm{NO} \rightarrow \mathrm{N}+\mathrm{O}(1.16 \mathrm{eV})$. The DFT calculations suggested that $\mathrm{NO}$ dissociation can be readily hindered even with a small amount of preadsorbed $\mathrm{O}$ atoms. There are two reasons. First, NO dissociation occurs dominantly at stepped sites, and such sites are in a low population on a catalyst. Second, O atoms prefer to adsorb at the stepped sites rather than the flat surface sites, and thus the stepped sites will always be populated first. 
By studying all the reactions on $\operatorname{Ir}\{111\}, \operatorname{Ir}\{211\}$ (a stepped surface), and O-covered $\operatorname{Ir}\{211\}$, namely $\mathrm{NO} \rightarrow \mathrm{N}+\mathrm{O}, \mathrm{N}+\mathrm{O} \rightarrow \mathrm{NO}, \mathrm{N}+\mathrm{N} \rightarrow \mathrm{N}_{2}, \mathrm{~N}+\mathrm{NO} \rightarrow \mathrm{N}_{2} \mathrm{O}$, and $\mathrm{O}+\mathrm{NO} \rightarrow \mathrm{NO}_{2}$, Liu, Jenkins, and King further revealed the physical origin of the O-poisoning [31]. In the $\mathrm{NO} \leftrightarrow \mathrm{N}+\mathrm{O}$ equilibrium, the preadsorbed $\mathrm{O}$ atoms destabilize the dissociated products ( $\mathrm{N}$ and $\mathrm{O}$ atoms) more strongly compared to their effect to the TS and to the adsorbed NO molecule. As a result, the $\mathrm{N}+\mathrm{O} \rightarrow \mathrm{NO}$ reaction is promoted to a large extent whereas the barrier of the $\mathrm{NO} \rightarrow \mathrm{N}+\mathrm{O}$ reaction is little changed. The bonding competition effect induced by the preadsorbed $\mathrm{O}$ atoms also switches the selectivity of $\mathrm{NO}$ reduction from $\mathrm{N}_{2}$ to $\mathrm{NO}_{2}$ production. The bonding competition energy cost of a $\mathrm{N}-\mathrm{O}$ pair is calculated to be larger than those of a $\mathrm{O}-\mathrm{O}$ pair and a $\mathrm{O}-\mathrm{NO}$ pair because of the bonding ability difference between the three different adsorbates. It was found that the preadsorbed $\mathrm{O}$ atoms tend to repel $\mathrm{N}$ atoms away from the stepped sites, which makes the O-plus reactions, such as the $\mathrm{O}+\mathrm{NO} \rightarrow \mathrm{NO}_{2}$, dominant in the $\mathrm{NO}$ reduction process.

\section{$\mathrm{CO}+\mathrm{O} \rightarrow \mathrm{CO}_{2}$ in $\mathrm{CO}$ oxidation}

\section{CO oxidation on transition metals}

$\mathrm{CO}$ oxidation on metal catalysts is one of the most studied systems in heterogeneous catalysis. It was generally believed that $\mathrm{CO}$ oxidation on transition metals follows Langmuir-Hinshelwood mechanism. Because $\mathrm{O}_{2}$ can readily dissociate on all transition metals at room temperatures, three elementary steps have been proposed during the $\mathrm{CO}$ oxidation: (i) $\mathrm{CO}$ adsorption on surfaces, (ii) $\mathrm{O}_{2}$ dissociation into $\mathrm{O}$ adatoms on surfaces, and (iii) $\mathrm{CO}+\mathrm{O} \rightarrow \mathrm{CO}_{2}$ reaction on surface. This straightforward mechanism is able to explain most of the experimental findings. I summarize the DFT references for CO oxidation in Table 1, and they are elaborated in the following subsections.

Table 1 Literatures of DFT-slab calculations for CO oxidation reaction on metal, metal oxide surfaces, and Au/oxide interfaces.

\begin{tabular}{|c|c|c|c|}
\hline & & Substrate & Ref. \\
\hline \multirow[t]{14}{*}{ Metal surfaces } & \multirow{7}{*}{$\begin{array}{l}\text { Close-packed } \\
\text { surface }\end{array}$} & $\mathrm{Ru}\{0001\}$ & $27,48,49$ \\
\hline & & $\operatorname{Rh}\{111\}$ & $27,50,53$ \\
\hline & & $\operatorname{Pd}\{111\}$ & $51,53,54$ \\
\hline & & & $42,51,53,54$ \\
\hline & & $\operatorname{Ir}\{111\}$ & 31 \\
\hline & & $\operatorname{Pt}\{111\}$ & $17,27,52,53$ \\
\hline & & $\mathrm{Cu}_{3} \operatorname{Pt}\{111\}$ & 52 \\
\hline & \multirow[t]{4}{*}{ Open surface } & $\operatorname{Pd}\{100\}$ & $42,51,53$ \\
\hline & & & 51,53 \\
\hline & & $\operatorname{Rh}\{100\}$ & 53 \\
\hline & & $\operatorname{Pt}\{100\}$ & 53 \\
\hline & \multirow[t]{3}{*}{ Stepped surface } & $\operatorname{Pd}\{211\}$ & 42 \\
\hline & & $\operatorname{Ir}\{211\}$ & 31 \\
\hline & & $\mathrm{Au}\{221\}$ & 67 \\
\hline \multirow[t]{3}{*}{ Metal oxide surfaces } & & $\mathrm{RuO}_{2}$ & $55,58,60-62$ \\
\hline & & $\mathrm{RhO}_{2}, \mathrm{PdO}_{2}, \mathrm{OsO}_{2}, \mathrm{PtO}_{2}$ & 55 \\
\hline & & $\mathrm{IrO}_{2}$ & 55,75 \\
\hline \multirow[t]{3}{*}{ Au/oxide interface } & & $\mathrm{Au} / \mathrm{MgO}$ & 68 \\
\hline & & $\mathrm{Au} / \mathrm{TiO}_{2}$ & 71,72 \\
\hline & & $\mathrm{Au} / \mathrm{TiO}_{2} / \mathrm{IrO}_{2}$ & 75 \\
\hline
\end{tabular}


$\mathrm{CO}$ oxidation on $\mathrm{Pt}\{111\}$ is a classical example of heterogeneous catalysis. The first attempt to reveal the surface reaction pathway of $\mathrm{CO}+\mathrm{O} \rightarrow \mathrm{CO}_{2}$ on $\mathrm{Pt}\{111\}$ was performed by Alavi, $\mathrm{Hu}$, and their coworkers [17], and similar results were also obtained later by Eichler and Hafner [47]. At the IS $1 / 4$ ML coverage, the CO sits on the top site and the $\mathrm{O}$ sits on the fcc hollow site (it might be pointed out that $\mathrm{CO}$ adsorption on transition metals is a difficult problem for DFT and it was shown that DFT can predict the wrong binding site for $\mathrm{CO}$ on $\mathrm{Pt}\{111\}$ [76]). At the TS, the CO sits on an off-top site being close to the $\mathrm{O}$, while the $\mathrm{O}$ is at a bridge site, as shown in Fig. 5a. At the FS, the nascent $\mathrm{CO}_{2}$ sits on the top site of $\mathrm{Pt}\{111\}$, weakly bonded on the surface. In addition, $\mathrm{CO}$ oxidation on other close-packed metal surfaces, $\operatorname{Ru}\{0001\}, \operatorname{Rh}\{111\}, \operatorname{Pd}\{111\}, \operatorname{Ir}\{111\}$, and an alloy surface $\operatorname{Cu}_{3} \operatorname{Pt}\{111\}$ have been performed [47-56]. It appears that the reaction pathways on the close-packed metal surfaces are very similar [49], which can be generalized as three common features.

- Activation of the $\mathrm{O}$ adatom. The $\mathrm{O}$ atom is activated from the initial hollow site to the bridge site in order to achieve the TS.

- $\quad$ Early TS. At the TS, the O-CO distance is long stretched, from $1.7 \sim 2.1 \AA$ depending on metals, compared to the gas-phase $\mathrm{C}-\mathrm{O}$ distance $(1.2 \AA)$ in $\mathrm{CO}_{2}$. The early TS of CO oxidation implies that the electronic structure of TS is similar to that of the individual adsorbed $\mathrm{CO}$ and $\mathrm{O}$ on surfaces.

- $\quad$ No bonding competition TS geometry [50]. This is because at the TS, no surface atom bonds simultaneously with both the $\mathrm{CO}$ and $\mathrm{O}$ (see Fig. 5a).

The key event in $\mathrm{CO}$ oxidation on close-packed metal surfaces is the $\mathrm{O}$ activation from the hollow site to the bridge site. By comparing the local density state of the $\mathrm{O}$ on the hollow and the bridge site, Zhang and $\mathrm{Hu}[50]$ explained why the $\mathrm{O}$ needs to be activated. At the hollow site, the $\mathrm{O}$ bonds with three metal atoms and its $p$ orbitals are largely saturated. As the $\mathrm{O}$ adatom is activated to the bridge site, one of its $p$ orbitals that originally bonds with a metal atom is freed and can further bond with the coming CO. This essentially reduces the direct Pauli repulsion between the $\mathrm{O}$ and the $\mathrm{CO}$ in the reaction.

In addition to the close-packed metal surfaces, $\mathrm{CO}$ oxidation on more open surfaces, such as $\{100\}$ surface for fcc metals, and the monatomic steps has also been examined by DFT. In the different contexts, $\mathrm{CO}$ oxidation on $\mathrm{Pd}\{100\}$ has been studied by three individual groups: Zhang and $\mathrm{Hu}$ [51], Eichler [53], and Hammer [42]. Eichler [53] also calculated systematically the reaction rate of CO oxidation on $\operatorname{Rh}\{100\}, \operatorname{Pd}\{100\}$, and $\operatorname{Pt}\{100\}$ based on transition-state theory, and compared them with the results on the corresponding close-packed flat surfaces. For the stepped surfaces, Hammer [42] studied $\mathrm{CO}$ oxidation on $\operatorname{Pd}\{211\}$ (stepped surface) and edged, missing-row reconstructed $\operatorname{Pd}\{311\}$; Liu et al. [31] studied CO oxidation on $\operatorname{Ir}\{211\}$. Typical TS structures of CO oxidation on $\{100\}$ and $\{211\}$ surfaces are shown in Figs. $5 \mathrm{~b}$ and c, respectively. DFT calculations showed that CO oxidation on $\{100\}$ surfaces has quite similar barriers to those on close-packed surfaces, while the barriers on the stepped
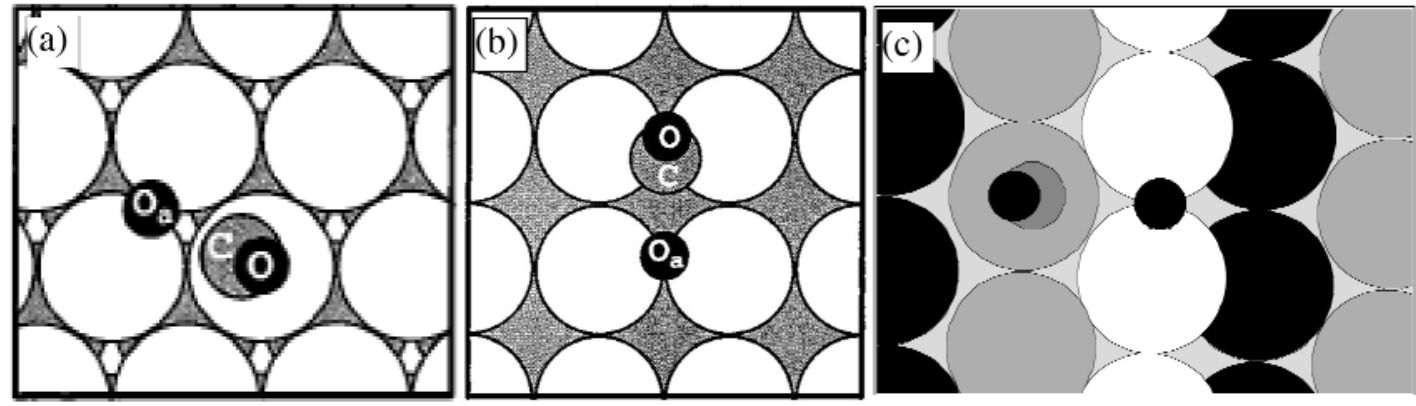

Fig. 5 Typical TSs for $\mathrm{CO}+\mathrm{O} \rightarrow \mathrm{CO}_{2}$ reaction on $\{111\}$ (a), $\{100\}$ (b), and $\{211\}$ (c) surfaces. (a) and (b) from [50]. 
surfaces are usually higher than those on the flat surfaces. For example, Zhang and Hu reported that on $\mathrm{Pd}\{100\}$ the barrier is $0.78 \mathrm{eV}$, while it is $0.93 \mathrm{eV}$ on $\mathrm{Pd}\{111\}$ at a $1 / 4 \mathrm{ML}$ coverage [51]. Eichler showed that on $\mathrm{Pt}\{100\}$ the barrier is $0.87 \mathrm{eV}$ and on $\mathrm{Pt}\{111\}$ it is $0.74 \mathrm{eV}$ [53]. On $\operatorname{Ir}\{211\}$, CO oxidation barrier is about $0.3 \mathrm{eV}$ larger than that on the flat $\operatorname{Ir}\{111\}$ [31], and the similar difference was observed for $\mathrm{CO}$ oxidation on $\operatorname{Pd}\{211\}$ and $\operatorname{Pd}\{100\}$ [42]. Because the close-packed flat surface is always the dominant face in real catalysts, DFT results indicate that CO oxidation is not very sensitive to surface structures.

It is worth mentioning that the DFT-calculated reaction barriers are in general well consistent with the experimental findings. For example, $\mathrm{CO}$ oxidation on $\mathrm{Pt}\{111\}$ has the lowest barrier $(0.7 \sim 0.8 \mathrm{eV})$, and on $\mathrm{Ru}\{0001\}$ has the highest barrier $(\sim 1.5 \mathrm{eV})$; $\mathrm{CO}$ oxidation on $\operatorname{Pd}\{111\}$ is sensitive to the $\mathrm{CO}$ coverage: at a high CO coverage, the barrier can be much lower $(\sim 0.9 \mathrm{eV})$ compared to the $\sim 1.4 \mathrm{eV}$ at a low $\mathrm{CO}$ coverage (this is due to the change of initial $\mathrm{CO}$ position on the surface at different $\mathrm{CO}$ coverages [50,53,54]). It should be noted that due to the usages of different calculation setups (basis sets, pseudopotential, etc.) and various DFT packages, the value of barriers in the same system can be different by around $0.1 \mathrm{eV}$ in different literature.

One of the fundamental questions in $\mathrm{CO}$ oxidation is what controls the reactivity change from metal to metal. It was initially suggested by several authors that the barrier of $\mathrm{CO}$ oxidation may be determined by the activation of the O. This comes from the fact that on going from the IS to the TS, the $\mathrm{O}$ apparently loses one bond with a surface metal atom (O activation) and this energy cost may contribute greatly to the barrier and is the reason for the reactivity difference among metals $[17,48]$. However, this argument is found to be too simplistic by Liu and Hu [27], and they pointed out that the activation of $\mathrm{CO}$ is also crucial. Based on a barrier decomposition analysis, they correlated the barriers with the total initial adsorption energies of the $\mathrm{CO}$ and $\mathrm{O}$ atom on the surfaces, as shown in Fig. 6 . The higher the surface can bond $\mathrm{CO}$ and $\mathrm{O}$, the higher the barrier is. The reason behind is that there is little interaction between the $\mathrm{CO}$ and $\mathrm{O}$ at the TS, and the barrier is largely due to the coactivation of $\mathrm{CO}$ and $\mathrm{O}$ from local minimum to the TS structure. Using the framework of extended Huckel theory, Glassey and Hoffman [56] also found that the dominant part of the reaction barrier comes from the surface-mediated coactivation of adsorbed $\mathrm{CO}$ and $\mathrm{O}$ atom, although during the $\mathrm{CO}$ oxidation, the $2 \pi$ orbital of $\mathrm{CO}$ interaction with the $\mathrm{O} 2 p$ orbitals is the principle driving force for the $\mathrm{CO}_{2}$ formation. This feature of $\mathrm{CO}$ oxidation also explains why $\mathrm{CO}$ oxidation is not very sensitive to the change of surface structure. Because the barrier of $\mathrm{CO}$ oxidation is largely determined by the total bonding energy of $\mathrm{CO}$ and $\mathrm{O}$, at stepped or edged surfaces where $\mathrm{CO}$ and $\mathrm{O}$ bond with the surface more strongly, the barriers are usually higher than those on the flat surfaces.

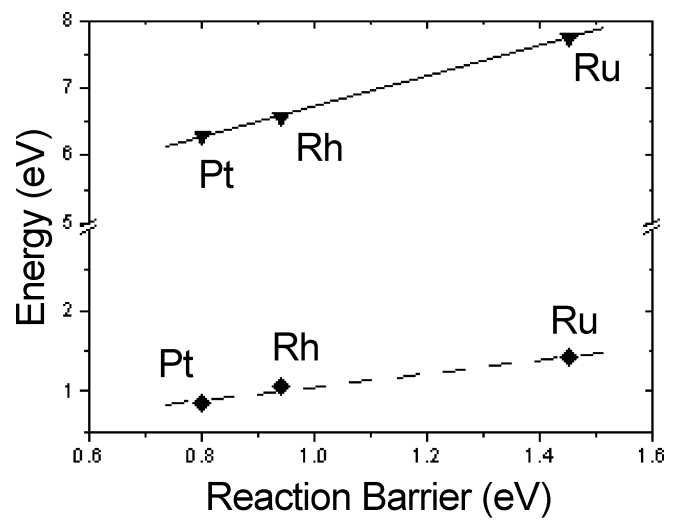

Fig. 6 Illustration of the $\mathrm{CO}$ oxidation barrier as a linear function of the total reactant-activation energy $\left(\Delta E_{\mathrm{O}}+\right.$ $\Delta E_{\mathrm{CO}}$ ) (dashed line) and the total chemisorption energy at the IS (solid line) on Ru, Rh, and Pt. As can be seen, . From [27]. 


\section{CO oxidation on late transition-metal oxides}

$\mathrm{Ru}$ is the poorest metal for $\mathrm{CO}$ oxidation at low $\mathrm{O}_{2}$ and $\mathrm{CO}$ pressures; however, it turns out to be superior at high $\mathrm{O}_{2}$ and $\mathrm{CO}$ pressures $[57,58]$. The enhanced catalytic ability has been attributed to the formation of $\mathrm{RuO}_{2}$ [57]. On other late transition metals, such as Pt and Pd, the similar phenomena were also observed in STM experiments [59]. Following the experimental observations, DFT calculations of $\mathrm{CO}$ oxidation on transition-metal oxides have been carried out to elucidate the mechanism.

$\mathrm{CO}$ oxidation on $\mathrm{RuO}_{2}\{110\}$ is the case being mostly studied. The reaction was first thought to proceed through the adsorbed $\mathrm{CO}$ that sits on the coordination-unsaturated Ru reacting with a lattice $\mathrm{O}$ of the $\mathrm{RuO}_{2}$ oxide, namely $\mathrm{CO}^{\text {cus }}$ and $\mathrm{O}^{\mathrm{br}}$, as suggested by the STM experiment of Over et al. [57]. DFT results following this mechanism showed that the barrier of $\mathrm{CO}^{\text {cus }}+\mathrm{O}^{\mathrm{br}}$ is around $1.2 \mathrm{eV}$ (see Liu et al. [58], Wendt et al. [60], Reuter and Scheffler [61]). In this mechanism, the barrier is already lower than that on pure Ru (around $1.5 \mathrm{eV}$ ). One step further, recent DFT studies by Reuter and Scheffler [61] identified a new mechanism: on the oxide surface, the adsorbed $\mathrm{CO}$ can react with the nearby adsorbed $\mathrm{O}$ to produce $\mathrm{CO}_{2}$, where both the $\mathrm{CO}$ and the $\mathrm{O}$ atom sit atop of the surface $\mathrm{Ru}$ atoms, namely $\mathrm{CO}^{\text {cus }}$ and $\mathrm{O}^{\text {cus }}$, as shown in Fig. 7. The barrier of $\mathrm{CO}^{\text {cus }}+\mathrm{O}^{\text {cus }}$ reaction is even lower, being $0.9 \mathrm{eV}$. This mechanism thus appears to be more likely, since $\mathrm{CO}$ oxidation on $\mathrm{Ru}$ oxides has been observed at $\sim 400 \mathrm{~K}[57,58]$. The presence of $\mathrm{O}^{\text {cus }}$ is also likely at the experimental conditions, which was verified by the thermodynamic calculations [61,62]. Using kinetic Monte Carlo method, Reuter et al. showed that the calculated reaction rate according to this new mechanism agrees well with the experimental value [62]. To generalize the phenomena for $\mathrm{CO}$ oxidation on the late transition-metal oxides, a comparative study of $\mathrm{CO}$ oxidations on the late transition-metal surfaces and their corresponding oxide surfaces were performed by Gong et al. [55]. They found that the $\mathrm{CO}^{\text {cus }}+\mathrm{O}^{\text {cus }}$ mechanism on oxides, as suggested by Reuter and Scheffler [61], can indeed provide a lower energy pathway compared to the reaction on the metal counterpart.

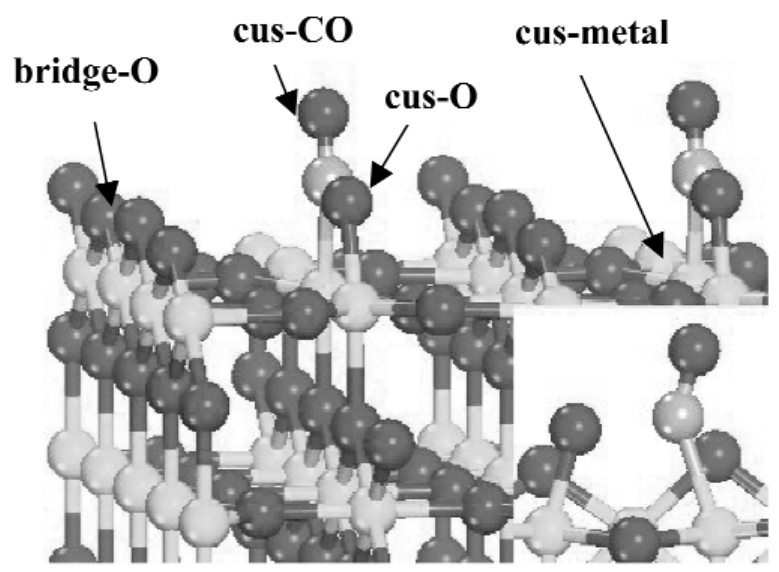

Fig. 7 The TS for $\mathrm{CO}+\mathrm{O} \rightarrow \mathrm{CO}_{2}$ on late transition-metal oxide (the inset is a close view of the TS). From [55].

\section{CO oxidation on oxide-supported Au particles}

Au/oxide catalysts, first shown by Haruta [63] in the late 1980s, possess a surprisingly high catalytic ability at low temperatures. The activity of $\mathrm{CO}$ oxidation was found to be very sensitive to the size of $\mathrm{Au}$ particles and also to the choice of oxides. Systems with $\mathrm{Au}$ supported on reducible oxide (e.g., $\mathrm{TiO}_{2}$, $\mathrm{Co}_{2} \mathrm{O}_{3}$ ) are generally more active than the ones with $\mathrm{Au}$ supported on irreducible oxides (e.g., $\mathrm{MgO}$, $\mathrm{SiO}_{2}$ ). The unexpected catalytic ability of Au-based catalysts has generated a lot of interest in the last 10 years. The experimental findings about Au-based catalysts have been reviewed (see refs. $[64,65]$ ). 
DFT studies by several groups have been carried out to clarify the mechanism. Lopez and Norskov [66] studied CO oxidation on a small Au cluster (10-atom). They found that the mechanisms with or without $\mathrm{O}_{2}$ dissociation are equally likely. On the other hand, Liu, Hu, and Alavi [67] reported that $\mathrm{O}_{2}$ dissociation on pure $\mathrm{Au}$, including flat, stepped Au surfaces and several Au clusters is not an easy step (barrier above $0.9 \mathrm{eV}$ ). They identified a reaction route involving $\mathrm{CO}$ reacting with molecular $\mathrm{O}_{2}$ at $\mathrm{Au}$ steps, which possess a barrier around $0.5 \mathrm{eV}$. A similar pathway was also found for $\mathrm{CO}$ oxidation over MgO-supported Au by Molina and Hammer [68]. The DFT calculations showed that the $\mathrm{O}_{2}$ adsorption energy is very low on $\mathrm{Au}(\sim 0 \mathrm{eV})$, and on $\mathrm{Au} / \mathrm{MgO}(\sim 0.2 \mathrm{eV})$, which imply that the $\mathrm{CO}+\mathrm{O}_{2}$ reaction may occur through a gas-phase $\mathrm{O}_{2}$ reacting with adsorbed $\mathrm{CO}$. Naturally, the probability of this type of reactions is very low compared to the conventional surface reactions through Langmuir-Hinshelwood mechanism. The other possible sites for $\mathrm{O}_{2}$ adsorption were suggested to be the charged Au clusters instead of the neutral ones. DFT-cluster studies of $\mathrm{O}_{2}$ adsorption on small neutral and charged Au clusters (e.g., [69,70]), seem to suggest an enhanced $\mathrm{O}_{2}$ adsorption on negatively charged $\mathrm{Au}$. Sanchez et al. [70b] showed that negative charged small Au clusters, such as $\mathrm{Au}_{8}$, which sit on the O-vacancy F-center of $\mathrm{MgO}$, can adsorb molecular $\mathrm{O}_{2}$ and catalyzes $\mathrm{CO}$ oxidization.

The first DFT calculation of $\mathrm{CO}$ oxidation on $\mathrm{Au} / \mathrm{TiO}_{2}$ interface was reported recently by Liu et al. [71]. They found that $\mathrm{O}_{2}$ can adsorb much stronger $(\sim 0.6 \mathrm{eV})$ at a $\mathrm{Au} / \mathrm{TiO}_{2}\{110\}$ interface than it on pure $\mathrm{Au}$, as shown in Fig. 8. They showed that the $\mathrm{TiO}_{2}$ support can induce a significant electron transfer from the $\mathrm{Au}$ to the $2 \pi$ anti-bonding states of $\mathrm{O}_{2}$ that sit at the interface between the metal and the oxide, which causes the $\mathrm{O}_{2}$ to be highly negatively charged. Such electron transfer not only enhances the binding of $\mathrm{O}_{2}$ on the catalyst, but also activates the $\mathrm{O}_{2}$. At the $\mathrm{Au} / \mathrm{TiO}_{2}$ interface, a facile bimolecular pathway $\left(\mathrm{CO}+\mathrm{O}_{2} \rightarrow \mathrm{CO}_{2}+\mathrm{O}\right.$ ) leading to $\mathrm{CO}_{2}$ formation (Fig. 8c) was identified, although the possibility of $\mathrm{O}_{2}$ dissociation is not excluded. The DFT calculations implied that the neutral Au clusters can be catalytically active as long as a right oxide support is selected [71,72].

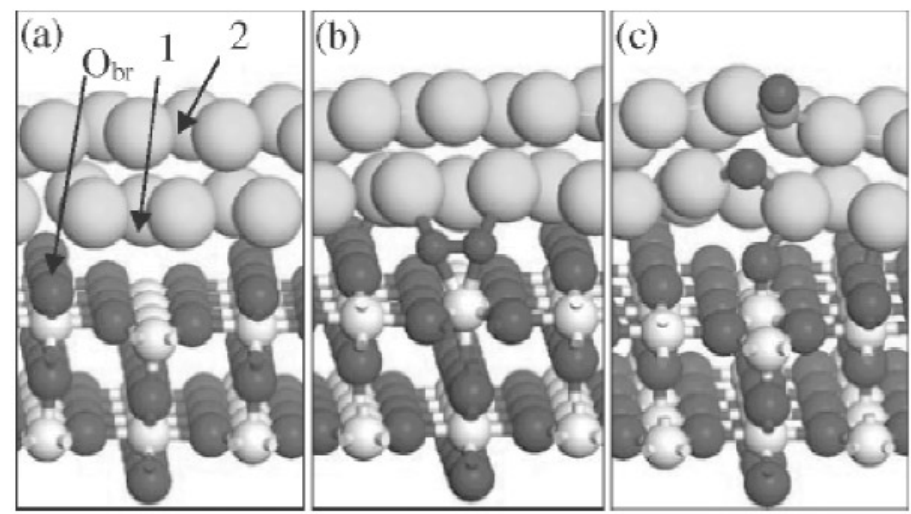

Fig. $8 \mathrm{CO}$ oxidation at the $\mathrm{Au} / \mathrm{TiO}_{2}$ interface. (a) A side view at the interface of the DFT-optimized $\mathrm{Au} / \mathrm{TiO}{ }_{2}$ system (sites 1 and 2 are the $\mathrm{Au}$ sites close to and away from the $\mathrm{TiO}_{2}$ surface, respectively). (b) $\mathrm{O}_{2}$ adsorption at the $\mathrm{Au} / \mathrm{TiO}_{2}\{110\}$ interface. (c) The TS for an adsorbed $\mathrm{CO}$ reacting with an $\mathrm{O}_{2}$ at the interface. From [71].

Because of the relatively low adsorption energy of $\mathrm{CO}$ and $\mathrm{O}_{2}, \mathrm{Au} / \mathrm{TiO}_{2}$ catalysts meet difficulty in applications at high temperatures, e.g., $500 \mathrm{~K}$. It has been suggested that multioxide supports might help to solve this problem. Experimentally, a $\mathrm{Au} / \mathrm{IrO}_{2} / \mathrm{TiO}_{2}$ catalyst was reported to be a good catalyst for oxidative reactions at high temperatures [73,74]. This enhanced high-temperature activity is confirmed by the recent DFT calculation by Liu, Jenkins, and King [75]. They showed that $\mathrm{O}_{2}$ can readily dissociate at the $\mathrm{Au} / \mathrm{IrO}_{2}$ interface and a $\mathrm{CO}+\mathrm{O} \rightarrow \mathrm{CO}_{2}$ reaction can proceeded with only $0.62 \mathrm{eV}$ barrier. Importantly, it was found that late transition-metal oxides can bond $\mathrm{Au}, \mathrm{CO}$, and $\mathrm{O}$ atoms more strongly than other oxides due to the $d$ states of metal cations being intrinsically more active. The ad- 
dition of these oxides can prevent the sintering of Au clusters and also improve the high-temperature activity of Au-based catalysts.

\section{CONCLUDING REMARKS}

The preceding sections serve to highlight some of recent progress in the theory of surface reactions, and their application to understand catalytic processes. DFT calculations on two representative reactions, $\mathrm{NO}$ dissociation and $\mathrm{CO}$ oxidation, are reviewed for this purpose. Because of their fundamental importance and relative simplicity compared to other large-molecule surface reactions, the two reactions have been extensively studied by DFT calculations. The results summarized here have demonstrated that the deep insight into catalytic processes can be gained by electronic structure calculations based on DFT.

The key points that this review intend to convey include:

- the rules governing the barrier of surface reactions

- the rules governing the reaction site of surface reactions

- unique features of metal surface reactions, for instance, the early (late) TS of surface association (dissociation) reactions; the bonding competition effect; and the surface structure sensitivity.

- mechanisms of NO dissociation on transition metals and the O-poisoning mechanism of NO reduction

- mechanisms of CO oxidation on transition metals and the origin of the barrier of CO oxidation

- mechanisms of $\mathrm{CO}$ oxidation on transition-metal oxides and Au-based catalysts

Obviously, there are still many open questions and challenges in the field. They should continue to provide opportunities for fruitful research for many years to come.

\section{ACKNOWLEDGMENTS}

The author would like to thank Dr. Peijun Hu, Dr. Stephen J. Jenkins, and Prof. Sir David A. King for their guidance and support. Queen's University of Belfast, the Isaac Newton Trust (Cambridge) are acknowledged for financial support.

\section{REFERENCES}

1. R. A. van Santen and M. Neurock. Catal. Rev. Sci. Eng. 37, 557 (1995).

2. J. L. Whitten and H. Yang. Surf. Sci. Rep. 218, 55 (1996).

3. Q. F. Ge, R. Kose, D. A. King. Adv. Catal. 45, 207 (2000).

4. B. Hammer and J. K. Norskov. Adv. Catal. 45, 71 (2000).

5. (a) M. G. Evans and N. P. Polanyi. Trans. Faraday Soc. 32, 1333 (1936); (b) R. A. Marcus. J. Phys. Chem. 72, 891 (1968).

6. F. Jensen. Introduction to Computational Chemistry, $1^{\text {st }}$ ed., John Wiley, New York (1999).

7. G. R. Darling and S. Holloway. Rep. Prog. Phys. 58, 1595 (1995).

8. B. Hammer and J. K. Norskov. Surf. Sci. 343, 211 (1995).

9. G. P. Brivio and M. I. Trioni. Rev. Mod. Phys. 71, 231 (1999).

10. P. Parr and W. Yang. Density Functional Theory of Atoms and Molecules, Oxford University Press, Oxford (1989).

11. P. Hohenberg and W. Kohn. Phys. Rev. 136, 864B (1964).

12. W. Kohn and L. Sham. Phys. Rev. 140, 1133A (1965).

13. J. P. Perdew, J. A. Chevary, S. H. Vosko, K. A. Jackson, M. R. Pederson, D. J. Singh, C. Fiolhais. Phys. Rev. B 46, 6671 (1992).

14. J. P. Perdew, K. Burke, M. Ernzerhof. Phys. Rev. Lett. 77, 3865 (1996). 
15. M. C. Payne, M. P. Teter, D. C. Allan, T. A. Arias, J. D. Joannopoulos. Rev. Mod. Phys. 64, 1045 (1992).

16. (a) See, for example, N. W. Ashcroft and N. D. Mermin. Solid State Physics, p. 113, Holt Saunders, Philadelphia (1976); (b) D. Vanderbilt. Phys. Rev. B 41, 7892 (1990); (c). R. Car and M. Parrinello. Phys. Rev. Lett. 80, 3650 (1998); (d). D. D. Johnson. Phys. Rev. B 38, 12087 (1988); (e). R. Fletcher. Practical Methods of Optimization, $2^{\text {nd }}$ ed., John Wiley, Chichester (1987).

17. (a) B. Hammer, K. W. Jacobsen, J. K. Nørskov. Phys. Rev. Lett. 69, 1971 (1992); (b) A. Alavi, P. Hu, T. Deutsch, P. L. Silvestrelli, J. Hutter. Phys. Rev. Lett. 80, 3650 (1998).

18. G. Henkelman, B. P. Uberuaga, H. Jonsson. J. Chem. Phys. 113, 9901 (2000).

19. (a) R. M. Wentzcovich, J. L. Martin, P. B. Allen. Phys. Rev. B 45, 11372 (1992); (b) I. Souza and J. L. Martins. Phys. Rev. B 55, 8733 (1997).

20. See, for example: (a) C. Stampfl, M. V. Ganduglia-Pirovano, K. Reuter, M. Scheffler. Surf. Sci. 500, 368 (2002); (b). K. Reuter and M. Scheffler. Phys. Rev. B 65, 035406 (2002); (c). A. Michaelides, M.-L. Bocquet, P. Sautet, A. Alavi, D. A. King. Chem. Phys. Lett. 367, 344 (2003).

21. See, for example: (a) S. Ovesson, A. Bogicevic, B. I. Lundqvist. Phys. Rev. Lett. 83, 2608 (1999); (b). E. W. Hansen and M. Neurock. J. Catal. 196, 241 (2000).

22. B. Hammer. Phys. Rev. Lett. 83, 3681 (1999).

23. V. Pallasana and M. Neurock. J. Catal. 191, 301 (2000).

24. A. Logadottir, T. H. Rod, J. K. Norskov, B. Hammer, S. Dahl, C. J. H. Jacobsen. J. Catal. 197, 229 (2001).

25. (a) Z.-P. Liu and P. Hu. J. Chem. Phys. 114, 8244 (2001); (b) A. Michaelides, Z.-P. Liu, C. J. Zhang, A. Alavi, D. A. King, P. Hu. J. Am. Chem. Soc. 125, 3704 (2003).

26. Z.-P. Liu, P. Hu, M.-H. Lee. J. Chem. Phys. 119, 6282 (2003).

27. Z.-P. Liu and P. Hu. J. Chem. Phys. 115, 4977 (2001).

28. Z.-P. Liu and P. Hu. J. Am. Chem. Soc. 124, 11568 (2002)

29. J. J. Mortensen, B. Hammer, J. K. Norskov. Surf. Sci. 414, 315 (1998).

30. K. Bleakley and P. Hu. J. Am. Chem. Soc. 121, 7644 (1999); M. Lynch and P. Hu. Surf. Sci. 458, 1 (2000).

31. Z.-P. Liu, S. Jenkins, D. A. King. J. Am. Chem. Soc. 126, 10746 (2004).

32. Z.-P. Liu and P. Hu. J. Am. Chem. Soc. 125, 1958 (2003).

33. (a) G. A. Somorjai. J. Mol. Struct. (THEOCHEM) 424, 101 (1998); (b) G. A. Somorjai. Introduction to Surface Chemistry and Catalysis, John Wiley, New York (1994).

34. S. Dahl, A. Logadottir, R. C. Egeberg, J. H. Larsen, I. Chorkendorff. Phys. Rev. Lett. 83, 1814 (1999).

35. B. Hammer. Phys. Rev. Lett. 83, 3681 (1999).

36. T. Zambelli, J. Wintterlin, J. Trost, G. Ertl. Science 273, 1688 (1996).

37. A. W. Brown and D. A. King. J. Phys. Chem. 104, 2578 (2000).

38. R. Burch, J. P. Breen, F. C. Meunier. App. Catal. B 39, 283 (2002).

39. P. I. Parvulescu, P. Grange, B. Delmon. Catal. Today 46, 233 (1998).

40. A. Eichler and J. Hafner. Chem. Phys. Lett. 343, 383 (2001).

41. A. Eichler and J. Hafner. J. Catal. 204, 118 (2001).

42. B. Hammer. J. Catal. 199, 171 (2001).

43. Z.-P. Liu, S. Jenkins, D. A. King. J. Am. Chem. Soc. 125, 14660 (2003).

44. D. Loffreda, F. Delbecq, D. Simon, P. Sautet. J. Chem. Phys. 115, 8101 (2001).

45. D. Loffreda, D. Simon, P. Sautet. J. Catal. 213, 211 (2003).

46. A. Logadottir, T. H. Rod, J. K. Norskov, B. Hammer, S. Dahl, C. J. H. Jacobsen. J. Catal. 197, 229 (2001).

47. A. Eichler and J. Hafner. Surf. Sci. 58, 433 (1999).

48. C. Stampfl and M. Scheffler. Phys. Rev. Lett. 78, 1500 (1997). 
49. C. J. Zhang, P. Hu, A. Alavi. J. Am. Chem. Soc. 121, 7931 (1999).

50. C. J. Zhang and P. Hu. J. Am. Chem. Soc. 122, 2134 (2000).

51. C. J. Zhang and P. Hu. J. Am. Chem. Soc. 123, 1166 (2001).

52. C. J. Zhang, R. J. Baxter, P. Hu, A. Alavi, M. H. Lee. J. Chem. Phys. 115, 5272 (2001).

53. A. Eichler. Surf. Sci. 498, 314 (2002).

54. P. Salo, K. Honkala, M. Alatalo, K. Laasonen. Surf. Sci. 516, 247 (2002).

55. X.-Q. Gong, Z.-P. Liu, R. Raval, P. Hu. J. Am. Chem. Soc. 126, 8 (2004).

56. W. V. Glassey and R. Hoffmann. Surf. Sci. 475, 47 (2001).

57. H. Over, Y. D. Kim, A. P. Seitsonen, S. Wendt, E. Lundgren, M. Schmid, P. Varga, A. Morgante, G. Ertl. Science 287, 1474 (2000).

58. Z.-P. Liu, P. Hu, A. Alavi. J. Chem. Phys. 114, 5956 (2001).

59. B. L. M. Hendriksen and J. W. M. Frenken. Phys. Rev. Lett. 89, 046101 (2002).

60. S. Wendt, A. P. Seitsonen, Y. D. Kim, M. Knapp, H. Idriss, H. Over. Surf. Sci. 505, 137 (2002).

61. K. Reuter and M. Scheffler. Phys. Rev. B 68, 045407 (2003).

62. K. Reuter, D. Frenkel, M. Scheffler. Phys. Rev. Lett. 10, 116105 (2004).

63. M. Haruta, N. Yamada, T. Kobayashi, S. Iijima. J. Catal. 115, 301 (1989).

64. F. Cosandey and T. E. Madey. Surf. Rev. Lett. 8, 73 (2001).

65. G. C. Bond and D. T. Thompson. Catal. Rev. Sci. Eng. 418, 319 (1999).

66. N. Lopez and J. K. Norskov. J. Am. Chem. Soc. 124, 11262 (2002).

67. Z.-P. Liu, P. Hu, A. Alavi. J. Am. Chem. Soc. 124, 14770 (2002).

68. L. M. Molina and B. Hammer. Phys. Rev. Lett. 90, 206101 (2003).

69. S. A. Varganov, R. M. Olson, M. S. Gordon, H. Metiu. J. Chem. Phys. 119, 2531 (2003).

70. (a) M. Okumura, Y. Kitagawa, M. Haruta, K. Yamaguchi. Chem. Phys. Lett. 346, 163 (2001); (b) A. Sanchez, S. Abbet, U. Heiz, W.-D. Schneider, H. Hakkinen, R. N. Barnett, U. Landman. J. Phys. Chem. 103, 9573 (1999).

71. Z.-P. Liu, X. Q. Gong, J. Kohanoff, C. Sanchez, P. Hu. Phys. Rev. Lett. 91, 266102 (2003).

72. L. M. Molina, M. D. Rasmussen, B. Hammer. J. Chem. Phys. 120, 7673 (2004).

73. M. Okumura, T. Akita, M. Haruta, Z. Wang, O. Kajikawa, O. Okada. Appl. Catal. B 41, 43 (2003).

74. T. Akita, M. Okumura, K. Tanaka, S. Tsubota, M. Haruta. J. Electron Microsc. 52, 119 (2003).

75. Z.-P. Liu, S. Jenkins, D. A. King. Phys. Rev. Lett. 93, 156102 (2004).

76. (a) P. J. Feibelman, B. Hammer, J. K. Norskov, F. Wagner, M. Scheffler, R. Stumpf, R. Watwe, J. Dumesic. J. Phys. Chem. B 105, 4018 (2001); (b) S. E. Mason, I. Grinberg, A. M. Rappe. Phys. Rev. B 69, 161401 (2004). 